\title{
Perspectivas da Colaboração no Ensino Remoto de Modelagem de Software: Um Relato de Experiência
}

\author{
Romualdo Azevedo, Alberto Castro e Bruno Gadelha \\ ${ }^{1}$ Instituto de Computação - Universidade Federal do Amazonas (UFAM) \\ 69.080 - 900 - Manaus - AM - Brasil \\ \{romualdo.costa, alberto, bruno\}@icomp.ufam.edu.br
}

\begin{abstract}
Software development is an inherently collaborative activity. Thus, developing skills of collaboration and teamwork, of criticism and self-criticism is essential for the training of future software engineers. In this context, the use of collaborative learning techniques is appropriate to stimulate the development of such skills. This paper presents an investigation about the use of the Peer Review collaborative learning technique in teaching software modeling using UML in different teaching modalities: face-to-face and remote teaching. As result, we present the main challenges, the differences, and the aspects of collaboration raised from the application of the technique in the two teaching modalities.
\end{abstract}

Resumo. O desenvolvimento de software é uma atividade inerentemente colaborativa. Assim, desenvolver habilidades de colaboração e trabalho em equipe, de crítica e autocrítica é essencial para a formação dos futuros engenheiros de software. Nesse contexto, o uso de técnicas de aprendizagem colaborativa se mostra apropriado para estimular o desenvolvimento de tais habilidades. Este artigo apresenta uma investigação acerca do uso da técnica de aprendizagem colaborativa de Revisão por Pares no ensino de modelagem de software utilizando UML em diferentes modalidades de ensino: presencial e ensino remoto. Como resultados são apresentados os principais desafios, diferenças e aspectos de colaboração decorrentes da aplicação da técnica nas duas modalidades de ensino.

\section{Introdução}

O processo de desenvolvimento de software é inerentemente colaborativo [Majdenbaum and Chaves 2020]. Afinal, desenvolver software é uma tarefa complexa onde são demandadas equipes com profissionais de diversas áreas como análise de requisitos, programação e testes de software que precisam comunicar-se durante um projeto [McLyndon et al. 2019]. Neste contexto, espera-se que estes profissionais tenham habilidades para colaborar em equipe, criticando e autocriticando-se durante as atividades [Mioto et al. 2019]. O desenvolvimento destas habilidades pode ser estimulado ainda nas universidades, enquanto os alunos aprendem conceitos acerca do desenvolvimento de software [Lima 2018]. Para tanto, os professores podem utilizar diversos artefatos como metodologias ou técnicas de aprendizagem colaborativa em sala de aula [Araújo 2018]. No entanto, promover a colaboração e a interação em equipe durante o ensino não-presencial é desafiador. 
Neste contexto, ensinar engenharia de software promovendo ainda o desenvolvimento de habilidades de crítica e autocrítica durante o distanciamento social instaurado pela pandemia causada pelo novo coronavírus exigiu que alunos e professores buscassem outros ferramentais para possibilitar a colaboração durante as aulas [Lopes 2017]. Neste contexto, tecnologias são adotadas como artefatos nas aulas remotas, possibilitando aos alunos e professores a interação e a discussão à distância [de Almeida et al. 2020]. Essas discussões, que antes ocorriam em sala de aula, passam a ocorrer por meio de sistemas colaborativos que possibilitam técnicas de aprendizagem colaborativas [Mesquita Junior 2017].

Desta forma, este artigo apresenta um relato de experiência acerca da aplicação da técnica de aprendizagem colaborativa de Revisão por Pares na disciplina de Engenharia de Requisitos e Análise de Sistemas (ERAS) que ocorreu na forma de Ensino Remoto Emergencial (ERE) na Universidade Federal do Amazonas. Esta disciplina contemplou o ensino de modelagem de software com diagramas Unified Modeling Language (UML). Para possibilidar a colaboração foi utilizada a ferramenta Model2Review, voltada para mediação da Revisão por Pares em contexto de ensino remoto. Assim, serão apresentadas as vantagens e desvantagens constituídas pela colaboração nesta modalidade de ensino. Os resultados obtidos no ensino remoto são então comparados com o resultado da aplicação da mesma técnica de Revisão por Pares no cenário do ensino presencial.

Este artigo segue organizado da seguinte forma: a Seção 2 apresenta alguns trabalhos relacionados ao ensino de modelagem de software de forma remota; na Seção 3 é apresentada a metodologia utilizada na pesquisa; a Seção 4 apresenta a Revisão por Pares no ensino de modelagem, contendo a condução do processo de ensino, os resultados obtidos e uma comparação entre esta pesquisa e outra que aplicou a Revisão por Pares no ensino presencial; e na Seção 5 as conclusões são apresentadas.

\section{Trabalhos Relacionados}

A imposição do isolamento social fez com que professores de computação mudassem suas práticas de educação. Nesse sentido, trabalhos discutem desde práticas metodológicas necessárias à experiências colaborativas no contexto do ensino remoto. Esta seção descreve alguns destes trabalhos.

O uso de tecnologias no ensino-aprendizado remoto e técnicas de aprendizagem colaborativa, fomentando a discussão sobre práticas pedagógicas e investigando o uso de tecnologias nesta modalidade de ensino tem sido temas de algumas investigações [Mesquita Junior 2017, de Freitas Farias et al. 2020]. Nesses trabalhos, os autores concluíram que o ensino remoto é desafiador, mas deixará mudanças positivas na educação e observaram desde as mudanças nas estratégias de ensino aos recursos tecnológicos disponíveis para oportunizar esta forma de ensino. Os autores apresentaram um panorama sobre os desafios e as tecnologias que dão suporte ao ensino remoto, expondo seus desafios e impactos.

Almeida e Silva Júnior de Almeida and da Silva Júnior 2020] discutem a colaboração no ensino remoto e apresentam o relato de uso da técnica colaborativa chamada Grupo de Verbalização/Grupo de Observação (GV-GO), aliada à Suíte Google. Nos estudos, aplicou-se a técnica em um curso superior de tecnologia com alunos da disciplina de Algoritmos II e com isso tornou-se possível concluir que a transposição da técnica 
GV-GO para uso com TDIC trouxe benefícios especialmente quanto à organização espacial dos discentes. A análise de dados coletados junto aos alunos indicou aceitação e relevância no uso da técnica em sala de aula/laboratório.

Os autores Costa et al. descrevem um estudo sobre o uso da técnica de aprendizagem colaborativa Revisão por Pares em aulas presenciais de modelagem de software [Costa et al. 2019]. Como resultado, os autores apresentam um conjunto de requisitos para a construção de uma ferramenta que dá suporte a técnica de Revisão por Pares para no ensino de modelagem de sistemas com UML.

Desta forma, esta pesquisa está relacionada com as diferentes vertentes investigadas nos trabalhos relacionados. Mesquita Junior [Mesquita Junior 2017] discutiu o uso de tecnologia no ensino remoto e Farias [de Freitas Farias et al. 2020] observou as mudanças nas estratégias de ensino. Já o trabalho de Almeida e Júnior [de Almeida and da Silva Júnior 2020] discute a aplicação de uma técnica de aprendizagem colaborativa em contexto remoto, relatando seus benefícios. Enquanto o trabalho de Costa et al. [Costa et al. 2019] relata um estudo de caso acerca da aplicação da técnica de Revisão por Pares em sala de aula. Desta forma, esta pesquisa vai ao encontro das pesquisas de Costa et al. [Costa et al. 2019] e Farias [de Freitas Farias et al. 2020] já que apresenta um relato sobre o uso de Revisão por Pares no contexto de ensino remoto de modelagem de software. Além disto, relata-se as diferenças na aplicação da técnica de Revisão por Pares nas modalidades do ensino presencial e remoto.

\section{Metodologia}

Este estudo foi realizado durante o Ensino Remoto Emergencial (ERE) ministrado os alunos do curso de Engenharia de Software da Universidade Federal do Amazonas. O ERE consiste em um curso que abrange o conteúdo da disciplina de Engenharia de Requisitos e Análise de Sistemas. O ambiente virtual de aprendizagem utilizado durante o curso foi o Moodle. No ambiente, o professor disponibilizou os conteúdos assíncronos do curso, fóruns de discussão e atividades para os discentes. Os momentos síncronos eram realizados por meio da plataforma Google Meet. E, para incentivar uma maior interação entre os alunos, utilizou-se o Model2Review em algumas das atividades de modelagem do curso como ferramenta de suporte à técnica de aprendizagem colaborativa Revisão por Pares.

Durante o curso, nas aulas síncronas, o professor explicava os diagramas da UML que os alunos deveriam utilizar para realizar a modelagem de algum software. Para cada diagrama, era realizado um exercício juntamente com os alunos como forma de exemplificação. Ao fim da aula, o professor deixava atividades acerca dos diagramas e estabelecia prazo para as entregas. Estas atividades deveriam ser desenvolvidas de forma assíncrona por estes alunos. Três dessas atividades, as que envolviam os diagramas da Casos de Uso, Classes e Sequência, foram realizadas por meio da ferramenta Model2Review, onde os alunos deveriam: (i) desenvolver sua solução, (ii) revisar a solução dos colegas, (iii) refletir sobre a avaliação recebida em sua solução e (iv) postar uma nova versão da sua solução como resposta à atividade.

Ao fim da atividade, os alunos foram convidados a responder um questionário sobre o uso da Model2Review como ferramenta de suporte para a Revisão por Pares. O questionário foi elaborado de acordo com o Modelo de Aceitação de Tecnologia (TAM - Technology Acceptance Model) [Venkatesh and Bala 2008] que avalia três constructos: 
utilidade, facilidade de uso e intenção de uso da tecnologia. Além disto, os alunos responderam sobre questões abertas em relação ao uso da ferramenta no contexto de ensino remoto. Assim, obteve-se o feedback dos alunos acerca da aplicação da técnica de aprendizagem colaborativa de Revisão por Pares no ensino remoto de modelagem de software. Desta forma, foi possível comparar as experiências entre a aplicação da Revisão por Pares no ensino remoto e presencial diante dos relatos dos participantes deste estudo, que utilizaram a ferramenta Model2Review para participar da Revisão por Pares, e o relato de outros alunos que passaram por estudos similares sobre colaboração com Revisão por Pares de forma presencial, durante o ensino de modelagem de software.

\section{Revisão por Pares no Ensino de Modelagem com UML}

De acordo com Barkley et al. [Barkley et al. 2014], a técnica de aprendizagem colaborativa Revisão por Pares consiste nas seguintes etapas: (i) em pares, conversam e descrevem ideias sobre o trabalho individualmente, onde cada estudante descreve suas ideias em um papel, fazendo perguntas e sugestões; (ii) assim, cada estudante, com conduta de pesquisador, guarda o que observou e que poderia ser útil para o seu próprio trabalho; (iii) estudantes escrevem em seus trabalhos individualmente; (iv) os alunos usam rascunhos em papel para edição por pares, os editores fazem marcas de revisão e comentários diretamente no papel, pontuando ou classificando o artigo com um formulário de avaliação e também preenchem e assinam este formulário indicando as classificações de cada um desses elementos; (v) cada autor revisa seu artigo, levando em consideração a edição de pares e; (vi) os autores anexam o formulário de avaliação ao rascunho final e o submetem ao professor.

Apesar das etapas estabelecidas pelos autores, a técnica de pode ser adequada para os distintos contextos de ensino. Assim, para este estudo consistiram em: (i) submissão da primeira versão do diagrama UML; (ii) revisão dos diagramas dos colegas e; (iii) envio da versão final do diagrama, após receber os feedbacks dos colegas em relação aos seus diagramas. Deste modo, na primeira etapa verifica-se como os alunos desenvolvem o primeiro modelo enquanto na segunda etapa desenvolve-se as habilidades de crítica nos alunos à partir do momento em que eles são estimulados a criticar os modelos dos colegas, e na terceira etapa desenvolve-se a autocrítica, já que os alunos devem revisar seus próprios diagramas baseados no feedback emitido pelos colegas durante a fase de revisão.

\subsection{Colaboração no Ensino Remoto}

A disciplina de Engenharia de Requisitos e Análise de Sistemas é ofertada aos alunos do quinto período do curso de Engenharia de Software da Universidade Federal do Amazonas de forma presencial. Porém, foi necessário adaptar as práticas pedagógicas para o contexto do ensino remoto devido ao isolamento social imposto decorrente da pandemia do COVID-19. Estas adaptações estão relacionadas ao plano de ensino, as provas foram substituídas por atividades assíncronas e os encontros presenciais substituídos por encontros síncronos via Google Meet. Assim, a condução do ensino de diagramas com UML nesta disciplina ocorreu em uma abordagem distinta da convencional, de forma totalmente remota.

A cada diagrama abordado pelo professor, era realizado um exercício exemplo para que os alunos pudessem tirar dúvidas e, posteriormente, ocorria uma atividade acerca 
do diagrama. Nesta atividade, o professor disponibilizava um cenário fictício extraído de um livro de exercícios contido na ementa da disciplina e estabelecia prazos para entregas assíncronas destas atividades e os alunos deveriam desenvolver o modelo de diagrama da UML solicitado, relacionado ao cenário proposto. Contudo, a interação ficaria restrita entre professor e aluno, e as atividades promovidas assim poderiam não possibilitar discussões entre os próprios alunos. Desta forma, a Revisão por Pares entrou como ferramental para promover a colaboração durante o ensino-aprendizagem de modelagem de software nesta disciplina.

Assim, a Revisão por Pares ocorreu durante as atividades dos diagramas de Casos de Uso, Classes e Sequência. O professor primeiramente explicou aos alunos, durante um encontro síncrono via Google Meet, que eles deveriam participar de uma atividade de Revisão por Pares sobre os três diagramas via ferramenta Model2Review pois ela constituía-se em uma atividade avaliativa. Explicou também que a atividade era parte de um estudo para uma pesquisa, onde os alunos poderiam disponibilizar seus dados para análise do estudo, caso desejassem, mas eram livres para apenas fazer a atividade e não disponibilizar seus dados. Desta forma, 21 alunos participaram da pesquisa, mas apenas 16 disponibilizaram seus dados para este estudo.

Desta forma, o professor utilizou a ferramenta Model2Review para mediar as três atividades. Para tanto, cadastrou nesta ferramenta a turma e estabeleceu as atividades com seus respectivos prazos e formulário de avaliação para cada diagrama. Os alunos tiveram quatro dias para participar de cada etapa, totalizando doze dias para participar da atividade completa. Assim, forneceu-se insumos para que os alunos participassem das atividades via ferramenta Model2Review, podendo promover a colaboração e possibilitando o desenvolvimento das habilidades de crítica e autocrítica nos alunos nessa modalidade de ensino. Enquanto isto, os alunos cadastraram-se na ferramenta. Então eles puderam verificar a a lista de turmas e associar-se à turma de ERE - Engenharia de Requisitos e Análise de Sistemas cadastrada pelo professor. Os alunos tiveram o prazo de um dia para se cadastrar devidamente na turma. Desta forma, a ferramenta mediou as atividades da técnica com base nos prazos estabelecidos pelo professor.

Os alunos desenvolveram seus modelos e submeteram suas respostas nas respectivas atividades. Em seguida, essa fase foi encerrada e deu-se início à fase seguinte, de revisão dos modelos, onde os alunos puderam verificar e revisar as atividades dos colegas delegadas pelo Model2Review. Assim, os alunos puderam responder ao formulário de avaliação cadastrado pelo professor e escrever comentários acerca de cada modelo submetido. Além disto, a ferramenta possibilitava a edição do modelo, ou seja, o aluno podia realizar anotações diretamente no diagrama do colega, estimulando o desenvolvimento da habilidade de crítica durante a atividade, mesmo em contexto de ensino remoto. A Figura 1 representa a tela de revisão dos modelos, utilizada pelos alunos durante a dinâmica na ferramenta Model2Review. 


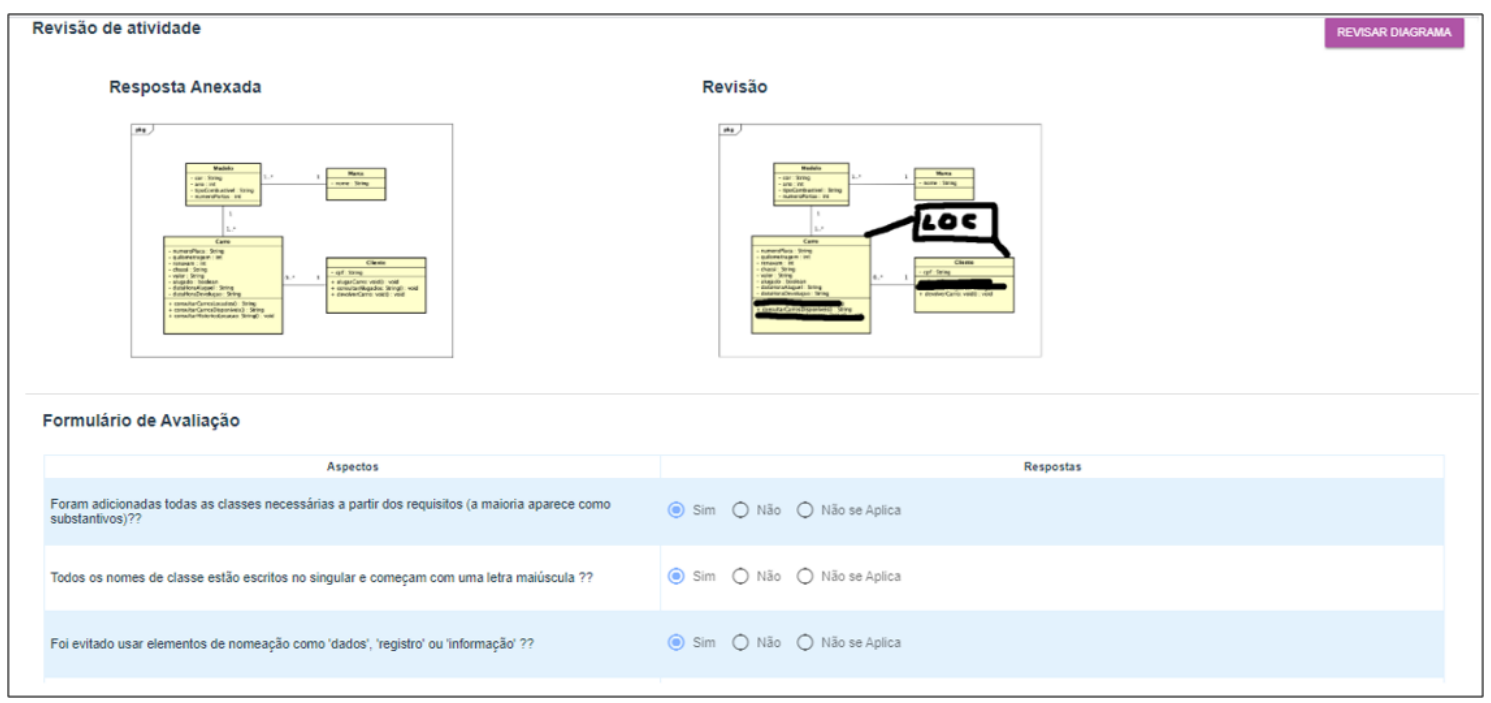

Figura 1. Tela correspondente à etapa de revisão da atividade em que obtém-se a visão geral do diagrama submetido, do diagrama revisado e do checklist a ser respondido

Ao fim da segunda etapa, os alunos foram direcionados a etapa de submissão da versão final, nesta etapa os alunos podiam verificar os feedbacks emitidos pelos seus colegas acerca dos seus diagramas. Ou seja, podiam verificar as anotações diretas no diagrama (caso houvesse), todas as respostas do formulário de avaliação e o comentário geral em relação a atividade. Com isto, estimulava-se o desenvolvimento da autocrítica, onde o aluno pode refletir sobre a sua primeira versão de modelo submetida e o que precisaria melhorar para submeter a versão final.

\subsection{Percepções Acerca da Colaboração no Ensino Remoto}

Após participarem das atividades de Revisão por Pares, os alunos foram convidados a responder um questionário acerca da ferramenta Model2Review. Para tanto, foi utilizado um questionário baseado no Modelo de Aceitação de Tecnologia (TAM), que avalia em percepções dos usuários durante a utilização de uma nova tecnologia a partir de três constructos: utilidade, facilidade e intenção de uso percebida da tecnologia [Venkatesh and Bala 2008]. Na Figura2 constam os dados das respostas dos alunos, onde as 13 perguntas foram divididas de acordo com seus constructos, a saber: utilidade percebida (perguntas de 1 a 4), facilidade do uso percebida (perguntas de 5 a 8 ) e sobre a intenção do uso da ferramenta (perguntas de 9 a 13). O questionário completo pode ser acessado em: https://doi.org/10.6084/m9.figshare.13523891. Ao concordarem com os termos da pesquisa, os alunos que disponibilizaram seus dados tinham menos de 30 anos sendo 62,5\% deles entre 18 e 22 anos. Além disso, 68,8\% dos participantes disseram que haviam participado de uma atividade de Revisão por Pares antes e $62,5 \%$ assinalaram que esta era a primeira vez que utilizavam uma ferramenta de mediação da técnica de Revisão por Pares em contexto de ensino remoto. 


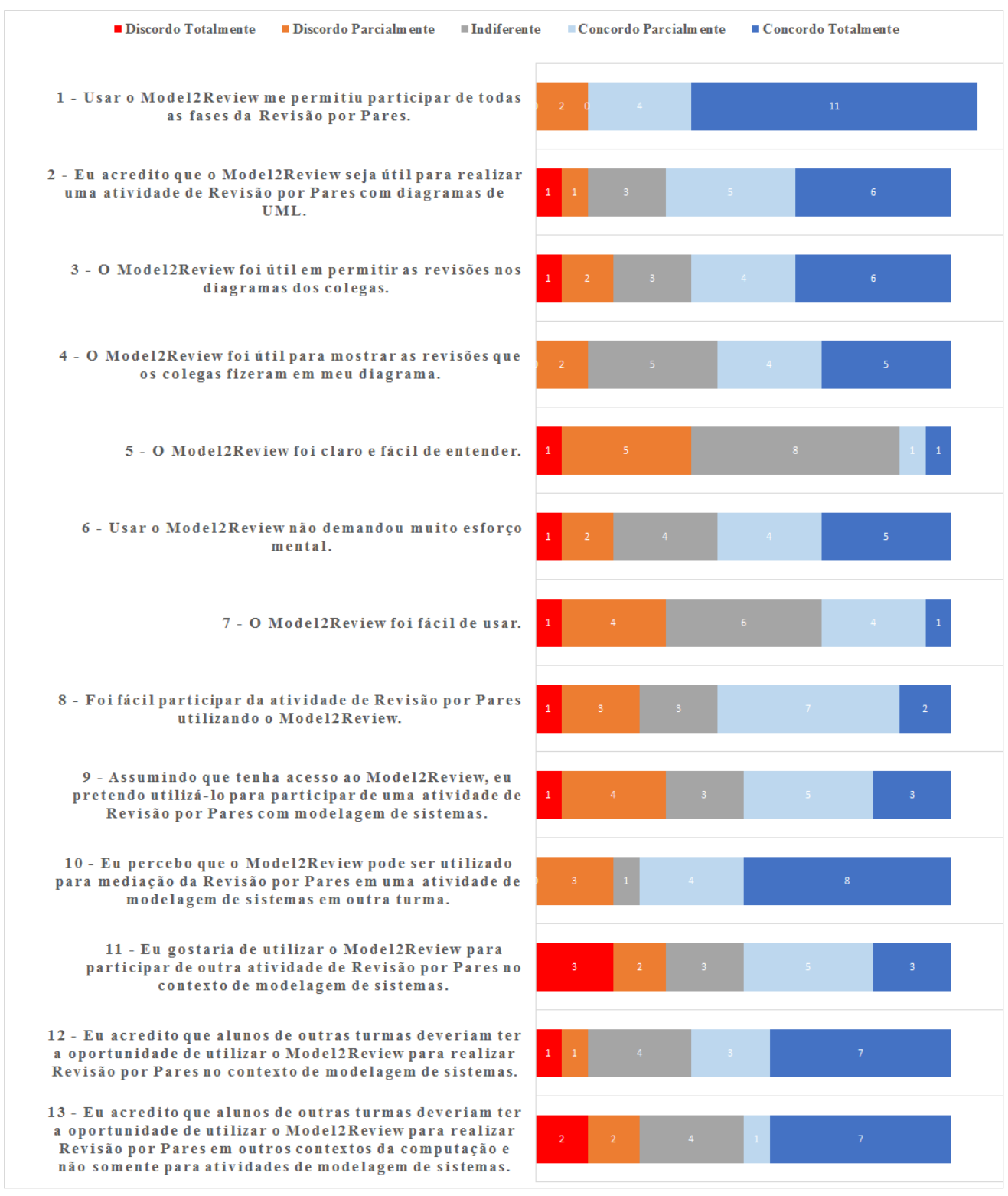

Figura 2. Análise das respostas do questionário TAM (Technology Acceptance Model)

As respostas do questionário revelaram as percepções dos alunos sobre a Model2Review. Eles concordaram sobre a utilidade da ferramenta para mediar a Revisão por Pares. Já nas perguntas sobre a facilidade de uso, os alunos concordaram que a Model2Review não demandou muito esforço mental. No entanto, alguns foram indiferentes enquanto à facilidade de uso. Isto talvez se deva ao fato da maioria dos alunos não terem participado de uma Revisão por Pares antes. No entanto, fazem-se necessários ajustes na ferramenta em questões de usabilidade. Acerca da intenção de uso futuro, enquanto alguns participantes disseram que usariam a ferramenta para outras atividades de modelagem, outros disseram que não. Isto pode ter ocorrido pelo fato de os alunos terem utilizado a ferramenta em três atividades seguidas, sendo diagrama de casos de uso, classes e sequência. Ou seja, eles desenvolveram o modelo, submeteram resposta, analisaram 
os feedbacks e conceberam a versão final em três atividades de modelagem seguidas por meio da Revisão por Pares, que é uma técnica interessante a princípio, mas que pode se tornar cansativa ao longo do tempo. No entanto, outro ponto positivo verificado no TAM foi a intenção de uso futuro da ferramenta, onde a maioria dos alunos concordaram que ela pode ser utilizada para mediar a Revisão por Pares durante a modelagem de software não só no ensino remoto, mas em outros contextos educacionais.

Além das questões fechadas do questionário, os alunos tiveram a oportunidade de discorrer, em questões abertas, sobre a experiência de colaborar durante o ensino remoto. Assim, eles puderam relatar suas dificuldades e facilidades nesta modalidade de ensino. Os alunos relataram que a ferramenta Model2Review foi pouco intuitiva e outros alunos relataram problemas acerca de sua usabilidade. É possível perceber isto durante as questões sobre como eles sentiram-se capazes em participar da revisão e o que acharam fácil de utilizar durante a experiência na ferramenta.

Ao serem questionados acerca de sentirem-se capazes de participar de totalmente da atividade de Revisão por Pares, os alunos fizeram comentários como: "Sim, pois pude revisar e ver as revisões feitas em meu diagrama."; "Sim, Porque consegui realizar todas as atividades"; "Sim, por ser intuitivo de utilizar quando se sabe sobre modelagem em UML."; "Sim, pelo fato de fácil entendimento da ferramenta."; "sim, a ferramenta oferece a possibilidade de realizar o processo do inicio ao fim". Apesar da maioria dos feedbacks positivos, tiveram alunos que responderam: "Não, pois meus colegas não corrigiram todos os meus diagramas." e "Não. Porque meus diagramas não foram revisados". Ou seja, o fato de alguns colegas deixarem de revisar as tarefas dos colegas foi um ponto negativo durante a colaboração. Já que no contexto remoto o professor consegue cobrálos apenas por email ou nos encontros síncronos.

Sobre a facilidade de uso da Model2Review, os alunos responderam: "Responder o questionário e escrever minhas observações."; "Escrever comentários"; "Depois que me familiarizei, não foi difícil algo.”; "o processo do checklist foi bem fácil e prático”. Ou seja, a aprendizagem colaborativa neste novo contexto contou com percepções positivas segundo os alunos. Afinal, participar de atividades colaborativas de forma remota não é trivial. No entanto, alguns alunos responderam a esse questionamento desta forma: "Apesar de problemas para retornar à uma página anterior e a ferramenta de edição não proporcionar a possibilidade de mudar a escala de espessura do pincel para desenhar em cima do diagrama apresentado, sim.”. Este relato em relação a navegação das páginas poderiam ser contornados com mais feedbacks por parte da ferramenta. Afinal, relataram que sentiam-se perdidos em determinados momentos em que utilizaram a ferramenta. Isto é um ponto negativo durante a colaboração à distância.

Em relação às dificuldades de colaborar a distância via ferramenta e quais funcionalidades poderiam ser incluídas na ferramenta, os alunos relataram: "Em relação a interface, os botões e as mensagens de feedback não são intuitivos. Ao submeter um diagrama, por exemplo, não há um retorno visual sobre o diagrama estar anexado mesmo ou não." ; "Dificuldades com a aplicação, muitas vezes me confundi e as informações não estavam claras e fáceis de achar, como a revisão feita pelo colega, só achei pois o mediador explicou como encontrar, tem erros mas acredito que tudo possa ser melhorado" ; "A ferramenta não possuía uma interface que permitisse voltar a pagina," ; "dar zoom nos diagramas". Apesar destes comentários, alguns alunos responderam que não tiveram 
dificuldades: "Sem problema algum", "Nenhuma" e "não".

Neste contexto, os alunos ainda relataram que a ferramenta possibilitou a interação entre os alunos, mediante a obtenção de outra solução acerca do mesmo problema. Outros relataram que verificar as revisões dos colegas foi uma facilidade, já que com isso puderam melhorar seus modelos. Relataram que o fato das revisões serem anônimas os auxiliou muito, pois os deixou mais a vontade na hora de refletir e criticar os modelos dos seus colegas. Os alunos relataram que as etapas de enviar diagrama, revisar e enviar versão final foram bem fáceis. Disseram ainda que o processo de revisão através de um checklist foi um facilitador, uma vez que eles conseguiam saber o que analisar no diagrama do colega.

Como sugestões para melhoria da ferramenta e assim uma melhor promoção da colaboração, os alunos destacaram aspectos relacionados à usabilidade do Model2Review. Como exemplo tem-se as citações: "Mais opções no momento de revisar o diagrama"; "As mensagens de feedback, o nome dos botões da ferramenta e o menu funcional"; "adicionar botão de voltar, todas as páginas, exceto login"; "Provavelmente opções de pincéis menores para indicar em que parte do diagrama eu vejo algo que poderia ser melhorado, e também uma mensagem ou algo que indique que você subiu a imagem do seu diagrama, porque não tem nada que indique que deu certo.”.

Apesar das dificuldades e sugestões de melhorias nota-se que a Revisão por Pares se apresentou como uma técnica de aprendizagem viável aos alunos de cursos de modelagem de software. Nota-se, ainda, que a ferramenta Model2Review cumpriu com o previsto na disciplina, possibilitando a colaboração no ensino remoto de modelagem de software. Através da aplicação da técnica com o uso da ferramenta, foi possível notar a evolução dos alunos em cada etapa das atividades realizadas, submetendo a atividade em primeira versão e depois contando com as funcionalidades da ferramenta para criticar os diagramas dos colegas e assim poder desenvolver um modelo melhor que o submetido na primeira versão.

\subsection{Comparação: Colaboração nas Modalidades de Ensino Remoto e Presencial}

Existem outros estudos na literatura relacionados à aplicação da Revisão por Pares no ensino presencial. Desta forma, busca-se nesta seção realizar uma breve reflexão acerca das diferenças entre a aplicação da Revisão por Pares no ensino remoto e no ensino presencial.

A comparação será entre esta pesquisa e um estudo realizado na Universidade Federal do Amazonas, onde a Revisão por Pares foi aplicada em uma turma de Engenharia de Requisitos e Análise de Sistemas em contexto presencial. No estudo presencial, os autores contaram com a participação de onze alunos do quinto período do curso de Engenharia de Software. Durante o estudo, a dinâmica ocorreu em apenas uma aula onde o professor estabeleceu um cenário para o desenvolvimento de um diagrama de casos de uso simples.

Os alunos dispuseram de 15 minutos para desenvolver a primeira versão do seu diagrama em uma folha de caderno. Depois, os alunos tiveram 10 minutos para realizar a revisão dos diagramas dos colegas. Para auxiliá-los na revisão, o professor disponibilizou um checklist para a avaliação de modelos de forma impressa. Por fim, os alunos tiveram mais 10 minutos para verificar as revisões dos colegas sobre os seus diagramas e desenvolver a versão final considerando as revisões recebidas. A Figura 3 contém um 
checklist preenchido manualmente durante a atividade de diagrama de Casos de Uso por um participante deste estudo.

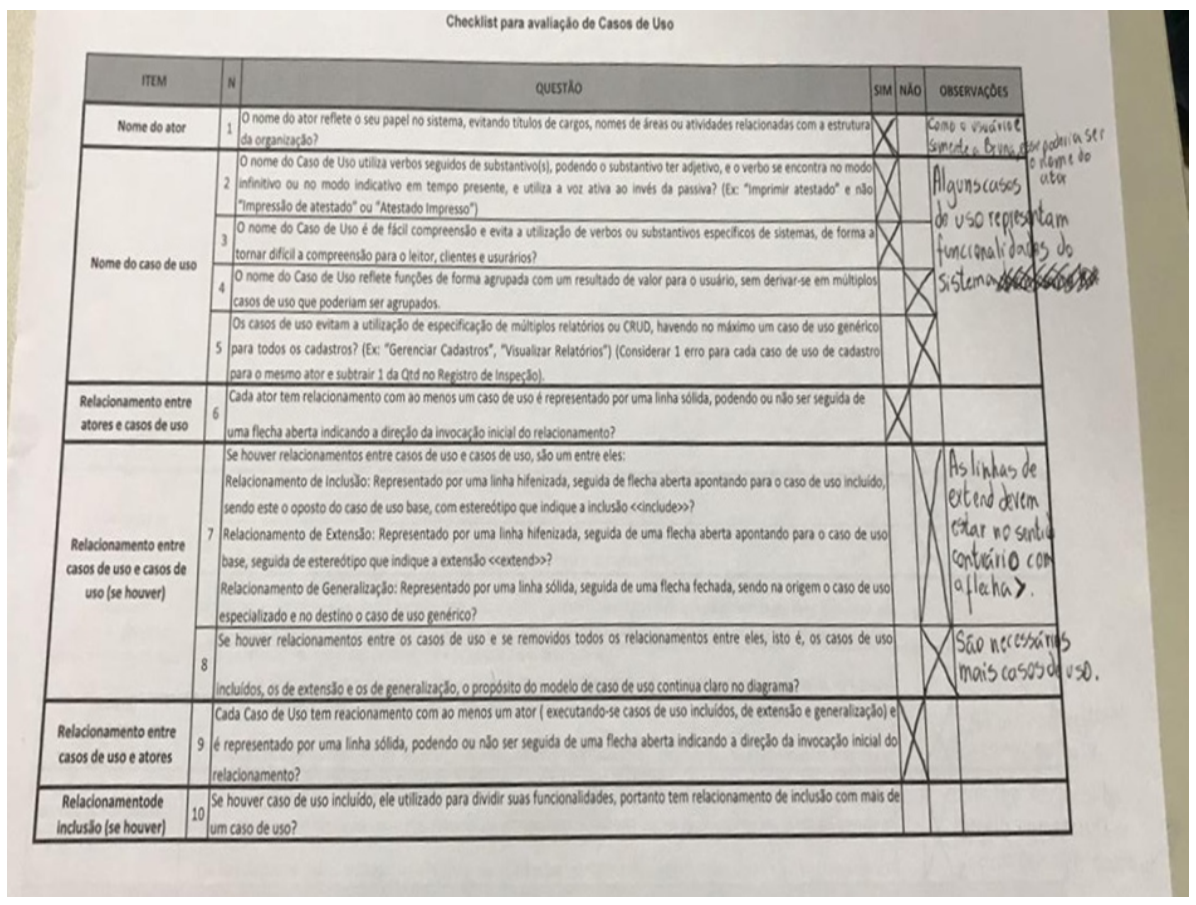

Figura 3. Preenchimento de checklist durante o ensino presencial

Desta forma, é possível perceber que presencialmente o professor pode realizar a atividade em apenas uma aula, para cada diagrama enquanto no ensino remoto é necessário de mais prazo, afinal os alunos estão em outros contextos e com outras atividades extra-classes. No entanto, a técnica ao ser realizada em contexto presencial limita professores e alunos a um tempo curto durante suas interações para raciocínio sobre o problema. A interação durante o ensino não-presencial propicia que alunos estejam em ambientes e momentos mais oportunos, de acordo com suas possibilidades e necessidades, para que consigam pensar sobre o problema e a colaboração. Além disto, a interação entre os alunos é distinta em cada modalidade. No ensino presencial, os alunos podem perguntar diretamente ao professor e sanar sua dúvida acerca da atividade, enquanto no ensino remoto o aluno precisa entrar em contato com o professor/monitor de forma assíncrona e esperar pelo feedback. No ensino remoto, o professor pode solicitar várias atividades de uma vez, como ocorreu nas três atividades de modelagem de software neste estudo. Já no ensino presencial isto é inviável, já que a cada aula é destinada a abordar um determinado diagrama. Pode-se considerar que a colaboração por meio do ensino remoto demandou tempo ao professor. Afinal, ele teria que configurar todas as etapas para a Revisão por Pares via ferramenta, enquanto no ensino presencial a atividade ocorreria em uma aula e ele controlaria as atividades durante o ato das etapas. Sobre o uso dos checklists, o professor necessitou imprimi-los e fazer a atribuição manual dos diagramas para revisão, enquanto que esta atividade é realizada automaticamente pela ferramenta Model2Review utilizada durante o ensino remoto.

Por outro lado, a ferramenta facilitou o fato de o professor controlar com mais pre- 
cisão a anonimidade dos revisores e autores durante a atividade. Durante o a colaboração sem mediação tecnológica mediante contexto de ensino presencial, essa tarefa requer mais esforço visto que os alunos geralmente conhecem as letras de seus colegas, suas folhas de caderno, e podem perceber a quem o professor direciona as tarefas. A colaboração por meio da Revisão por Pares possibilitada aos alunos em contexto remoto ou presencial tem suas diferenças, mas as características dependem de como as atividades são conduzidas. Caso o professor definisse mais de um revisor por rodada, o tempo em sala de aula deveria ser maior, pois o aluno teria que copiar o modelo para outro revisor. Já com a ferramenta Model2Review isto é perfeitamente possível visto que ela disponibiliza automaticamente as revisões de acordo com as configurações estabelecidas pelo professor.

\section{Conclusão e Perspectivas Futuras}

Os sistemas colaborativos auxiliam diversos contextos de ensino bem como o ensino remoto, em diversas áreas do saber como a Engenharia de Software. Com isto, este trabalho visa contribuir por meio de um relato de experiência sobre a colaboração no ensino de modelagem de sistemas, descrevendo como foi possível promover a colaboração por meio da técnica de Revisão por Pares mediada pelo sistema colaborativo Model2Review e quais foram as dificuldades, facilidades e sugestões de melhorias para o sistema utilizado nesta pesquisa. Além disto, foi necessário descrever as mudanças do ambiente presencial de ensino para o ambiente remoto. Com a mudança, foi possível perceber que os estudantes puderam continuar desenvolvendo no ensino remoto as habilidades de crítica e autocrítica, requerida pelos engenheiros de software no mercado de trabalho. No entanto, tiveram que adaptar-se a um novo cenário de ensino que não estavam habituados. Outro fator percebido, é que a colaboração promove a interação entre os alunos neste momento em que o ensino ocorre com distanciamento social. As limitações desta pesquisa compreendemse aos diferentes contextos do estudo e a participação dos alunos. Enquanto o primeiro estudo ocorreu no ensino presencial, o segundo ocorreu em contexto remoto. Assim, professores e alunos necessitaram adaptar-se em suas formas de comunicação, por exemplo: durante a atividade de Revisão por Pares o professor enviava e-mails aos alunos para cobrar suas participações na dinâmica, já no ensino presencial o aluno pode faltar e perder a dinâmica completa em um dia. Sobre ameaças à validade, pode-se relatar que o questionário TAM explana as percepções acerca da ferramenta, mas poderiam haver questões acerca do aprendizado dos alunos nos diferentes contextos. A comparação entre a colaboração no ensino remoto e no ensino presencial, utilizando a técnica de Revisão por Pares, é útil neste artigo para obter-se uma reflexão entre as diferenças de cada modalidade de ensino e como as duas podem serem utilizadas em conjunto. Como trabalhos futuros, é possível que sejam realizadas as melhorias sugeridas na ferramenta Model2Review para promover de forma melhor a técnica de Revisão por Pares durante o aprendizado de modelagem de software. Além disto, é possível realizar um estudo acerca da colaboração no ensino à distância, que é outra modalidade de ensino. Em relação a ferramenta $M o$ del2Review, pode ser realizado um estudo acerca da usabilidade, para promover melhores experiências de uso futuramente.

\section{Agradecimentos}

O presente trabalho foi realizado com apoio da Coordenação de Aperfeiçoamento de Pessoal de Nível Superior - Brasil (CAPES) - Código de Financiamento 001. Além deste, 
esta pesquisa, conforme previsto no Art. 48 do decreto $n^{\circ}$ 6.008/2006, foi parcialmente financiada pela Samsung Electrônica da Amazônia Ltda, nos termos da Lei Federal $\mathrm{n}^{\mathbf{o}}$ 8.387/1991, através de convênio $\mathrm{n}^{\circ}$ 003/2019, firmado com o ICOMP/UFAM. A pesquisa também contou com apoio da FAPESP, Processo N: 2020/05191-2.

\section{Referências}

Araújo, W. C. d. (2018). A inserção no mercado de trabalho: desenvolvimento de habilidades sociais para universitários. Dissertação de Mestrado. Universidade de Taubaté.

Barkley, E. F., Cross, K. P., and Major, C. H. (2014). Collaborative learning techniques: A handbook for college faculty. John Wiley \& Sons.

Costa, R., Chourio, P., Castro, A., and Gadelha, B. (2019). Revisão por pares na aprendizagem de modelagem de sistemas: concepção de uma ferramenta de suporte. In Brazilian Symposium on Computers in Education (Simpósio Brasileiro de Informática na Educação-SBIE), volume 30, page 1975.

de Almeida, E. G., de França Leite, K. L., de Sousa Ferreira, L., and de Farias, M. S. (2020). Ensino remoto e tecnologia: Uma nova postura docente na educação póspandemia. In Anais VII Congresso Nacional de Educacao.

de Almeida, W. S. and da Silva Júnior, A. F. (2020). Ensino-aprendizagem com abordagem colaborativa: Aliando técnica pedagógica com tecnologias digitais de informação e comunicação. In Anais do XXVI Workshop de Informática na Escola, pages 199-208. SBC.

de Freitas Farias, M. A., Júnior, G. P. S., Moraes, H. L. B., and do Nascimento, S. M. (2020). De ensino presencial para o remoto emergencial: adaptações, desafios e impactos na pós-graduação. Interfaces Científicas-Educação, 10(1):180-193.

Lima, T. d. (2018). Uma análise de soft skills na visão dos profissionais da engenharia de software. Monografia. Universidade do Vale do Rio dos Sinos.

Lopes, M. S. d. S. (2017). Ambiente colaborativo para ensino aprendizagem de programação integrando laboratório remoto de robótica. Escola Politécnica.

Majdenbaum, A. and Chaves, M. (2020). Comunicação em projetos de desenvolvimento global de software: A visão dos praticantes. Gestão \& Regionalidade, 36(107).

McLyndon, S. d. L., Farias, K., Barbosa, J., Gonçales, L., and Bishoff, V. (2019). Umlcollab: Uma abordagem híbrida para modelagem colaborativa de modelos uml. In Anais do XV Simpósio Brasileiro de Sistemas de Informação, pages 231-238. SBC.

Mesquita Junior, P. R. d. S. (2017). Uma ferramenta de aprendizagem colaborativa em pares apoiada por rede social. Master's thesis, Universidade Federal de Pernambuco.

Mioto, F., Petri, G., von Wangenheim, C. G., Borgatto, A. F., and Pacheco, L. H. M. (2019). bases21-um modelo para a autoavaliação de habilidades do século xxi no contexto do ensino de computação na educação básica. Revista Brasileira de Informática na Educação, 27(01):26.

Venkatesh, V. and Bala, H. (2008). Technology acceptance model 3 and a research agenda on interventions. Decision sciences, 39(2):273-315. 